\title{
autêntica
}

\author{
ARTIGOS
}

\section{Impactos da pós-graduação stricto sensu na formação de professores de português da educação básica do distrito federal}

Vidiane Casimiro da Silva Lisiane de Oliveira Porciúncula

\begin{abstract}
RESUMO:
Este trabalho procurou investigar o impacto do crescimento da Pós-graduação stricto sensu na formação de professores de português da Educação básica que atuam na rede pública de ensino do Distrito Federal (DF), avaliando o comparativo entre o crescimento da Pós-graduação stricto sensu, nas áreas de Educação e Letras, nos últimos 10 anos com a relação de professores da Educação Básica atuantes na rede pública de ensino do DF que ingressaram e obtiveram os títulos de mestrado e/ou doutorado no mesmo período, possibilitando observar a evolução da formação continuada dos professores nesse nível de ensino. Também foram apontados aspectos que dizem respeito ao Sistema Nacional de Pós-graduação e o papel da CAPES no incentivo da formação continuada de professores em nível de Pós-graduação stricto sensu. Pesquisas realizadas sobre a formação continuada de professores foram analisadas. As conclusões confirmam o avanço no envolvimento de professores da Educação Básica atuantes na rede pública de ensino do DF com a Pós-graduação stricto sensu e ao mesmo tempo a importância de esforços adicionais de incentivo para um crescimento mais expressivo de ingressos e titulações.
\end{abstract}

\section{PALAVRAS-CHAVE:}

Pós-graduação stricto sensu. Formação continuada de professores. Educação básica.

\begin{abstract}
:
This study sought to investigate the impact of stricto sensu post-graduate growth in portuguese teachers training of basic education who work in DF's public school, analyzing the growth of stricto sensu post-graduate in the last 10 years in Education and Languages' areas together with the data of basic education teachers working in the DF's public school system who obtained the titles of Masters and /or PhD in the same period, making it possible to observe the evolution of the continuing education of teachers at this level of education. It also pointed out aspects concerning the National System of Post-Graduate and the role of CAPES in the induction of teachers' continuing education at this level of studies. Researches on continuing teacher education were analyzed. The findings confirm the progress in the involvement of basic education teachers active in DF's public education with stricto sensu post-graduate and at the same time the importance of further efforts incentive for a more significant growth of incomes and entitlements.
\end{abstract}

\section{KEYWORDS:}

Stricto sensu post-graduate. Continuing education of teachers. Basic education. 


\section{INTRODUÇÃO}

Nos últimos anos, a velocidade do desenvolvimento econômico, fruto da ação de globalização crescente, exige das escolas do setor público e privado alto padrão de qualidade a fim de permitir bons resultados face à concorrência. O desenvolvimento social periódico provoca a necessidade de busca por recursos humanos qualificados gerando novas exigências de ensino para a sociedade exigindo a renovação continua dos objetivos instituídos para a formação de professores. Portanto, muitas mudanças são necessárias para melhorar os resultados de aprendizagem na educação básica, pilar da educação brasileira, e a atuação do professor destaca-se como fundamental nessas mudanças.

Diante desse cenário, o governo brasileiro vem criando diversas políticas de incentivo a capacitação docente. A Lei No 13.005, de 25 junho de 2014, trata sobre o Plano Nacional de Educação - PNE para o decênio 20112020. Nele constam metas e estratégias que deverão ser cumpridas no prazo de vigência do PNE - 2011/2020. A meta 16 é "formar 50 \% dos professores da Educação Básica em nível de Pós-graduação lato e stricto sensu, garantir a todos formação continuada em sua área de atuação." A partir de 2007, a Coordenação de Aperfeiçoamento de Pessoal de Nível Superior - CAPES - passou a atuar na formação de professores da Educação básica aumentando a abrangência de suas ações no desenvolvimento de pessoal qualificado no Brasil e no exterior.

O ensino-aprendizagem de Língua Portuguesa apresenta grandes dificuldades no alcance de índices positivos. Segundo o Indicador de Alfabetismo Funcional - INAF de 2001 a 2011, desenvolvido pelo Instituto Paulo Montenegro e a ONG Ação Educativa, "o percentual da população alfabetizada funcionalmente foi de $61 \%$ em 2001 para 73\% em 2011, mas apenas um em cada 4 brasileiros domina plenamente as habilidades de leitura, escrita e matemática". Para Terezinha Nunes (1992):

Não existe dúvida de que a gramática desempenhe um papel na leitura. Quando as crianças começam a ler, elas rapidamente compreendem que o significado e a gramática das sentenças escritas oferecem indicações importantes, auxiliando-as na decodificação de palavras de difícil leitura. As crianças usam parte das sentenças para predizer ou antecipar as palavras que virão a seguir no texto e essa antecipação facilita a leitura.

Visto que a Língua Portuguesa é a base do ensino brasileiro, o desempenho adequado em seu ensino-aprendizagem é fundamental para alcançar o desenvolvimento correspondente na aprendizagem de outras tantas disciplinas. Segundo o Instituto Nacional de Estudos e Pesquisas Educacionais Anísio Teixeira - INEP, a Prova Brasil, promovida desde 2005, realiza a avaliação de desempenho dos estudantes da educação básica nas áreas de Língua Portuguesa e Matemática e oferece resultados por escola, município, Unidade da Federação e país. Também são aplicados questionários socioeconômicos à comunidade escolar e aos estudantes. Os resultados alcançados nessas provas, das quais as médias de desempenho subsidiam o cálculo do Índice de Desenvolvimento da Educação Básica - IDEB, realizado pelo INEP, apresentam a baixa qualidade da educação e permitem reconhecer as peculiaridades regionais, podendo comparar diferentes escolas e constatar que a oferta educacional não é igual para todos.

No Distrito Federal - DF as notas do IDEB, revelam que os resultados veem se mantendo ou aumentado timidamente em todas as modalidades de ensino nos últimos anos. Porém, as metas instituídas para 2013 foram obtidas apenas na $4^{\mathrm{a}}$ serie $/ 5^{\circ}$ ano da educação básica. Para a $8^{\mathrm{a}}$ serie $/ 9^{\circ}$ ano o resultado em 2013 


\title{
autêntica
}

foi de 3.9 enquanto a meta para esse ano era de 4.1. Já na $3^{a}$ serie do Ensino Médio o DF não alcançou as metas de 2011 e 2013

\section{PANORAMA DAS PESQUISAS SOBRE FORMAÇÃO CONTINUADA}

A origem e a urgência de capacitação profissional docente, e em tantos outros ramos, não são por acaso. Segundo Gatti (2008), essa necessidade de formação tem base histórica em condições emergentes na sociedade contemporânea, nos desafios colocados aos currículos e ao ensino, nos desafios postos aos sistemas pelo acolhimento cada vez maior de crianças e jovens, nas dificuldades do dia-a-dia nos sistemas de ensino, anunciadas e enfrentadas por gestores e professores e constatadas e analisadas por pesquisas.

Para Rigolon (2007):

\begin{abstract}
Muitos têm sido os estudos e debates em torno da formação continuada de professores e do trabalho docente. Autores como, Fusari (1997), Nóvoa (1998), André (2000), Mizukami (2002), Oliveira (2003), Souza (2005) e Tardif (2005) têm se preocupado com o processo de trabalho nas escolas diante das políticas educacionais. No final da década de 1990, a posição declarada do MEC era a de que a "a formação de que dispõem os professores hoje no Brasil não contribuiu para que seus alunos tivessem sucesso nas aprendizagens escolares" (MEC, 1999).
\end{abstract}

Segundo o INEP, capacitar os professores é a opção mais viável para melhorar o desempenho dos alunos conforme estudo do Instituto Ayrton Senna e do Boston Consulting Group sobre a Formação Continuada de Professores no Brasil, que apresenta desafios e oportunidades relacionados à formação continuada de docentes no Brasil, e afirma que estudantes expostos a bons professores aprendem de $47 \%$ a $70 \%$ a mais do que aprenderiam em média em um ano escolar. Para Leite (2010), um professor bem formado, motivado, com condições de trabalho adequadas e envolvido em um processo de formação contínua, que Ihe forneça elementos para a constante melhoria de sua prática, é o elemento mais importante para a educação de qualidade.

Muito se tem avançado na formação continuada de professores da educação básica na Pós-graduação stricto sensu, mas a ligação entre pesquisa e professor ainda precisa progredir. Na percepção de Ludke (2012):

A questão da pesquisa do professor da educação básica, ou do professor pesquisador, além das dificuldades de natureza material, organizacional e de formação, ainda sofre as de cunho epistemológico (que pesquisa é essa? Como se define, como se reconhece?) e até ideológico (será bom confundir o trabalho do professor e o do pesquisador?). Mas alguns argumentos poderosos se levantam para neutralizar esses obstáculos; o mais forte deles, a nosso ver, aponta a atividade de pesquisa e a formação para ela como importantes aliados do desenvolvimento profissional do professor.

A prática de pesquisa, segundo Erickson (1989), é decisiva para ajudar o professor da educação básica a conquistar sua autonomia plena, a sair da situação de dependência, quase de imaturidade, em relação aos professores do ensino superior, na qual ainda se encontra.

No estudo realizado por Lüdke; Rodrigues e Portella (2012) sobre o mestrado como via de formação de professores da educação básica para a pesquisa, procurou-se investigar como esse nível de ensino desempenha sua função como preparador para a realização de atividades de pesquisa principalmente para o professor. Embora os cursos de Pós-graduação na área de Educação venham se consolidando ao longo dos 
anos, segundo as autoras, foi no Plano Nacional de Pós-graduação (PNPG) 2005-2010 que os professores da educação básica passaram a ser contemplados explicitamente na formulação das políticas educacionais relativas a esse nível de ensino.

Na conclusão do estudo, as autoras ressaltam que as razões que levaram professores da educação básica a procurarem o curso de mestrado foram variadas, desde problemas de natureza prática, de suas escolas, até questões teóricas, políticas e também relativas às suas próprias carreiras e ao desenvolvimento profissional.

De volta ao trabalho nas escolas, os professores manifestaram a visão do que representou o mestrado e todos se declararam enriquecidos com a experiência vivida no mestrado, e embora não tenham encontrado a solução pronta para o seu problema de pesquisa, puderam discutir suas questões de modo satisfatório e enriquecedor, como se espera que aconteça na prática de pesquisa.

As reflexões dos professores de educação básica recém-mestrandos mostram uma importante evolução, não precisamente como previsto, mas talvez atingindo um alvo bem mais amplo.

A pesquisa também possibilitou mostrar que a parceria entre Universidade e educação básica, pela via do mestrado de professores, propiciou a discussão de temáticas que interessam a ambas, constatando que os professores mestrandos conseguiram conciliar seus temas de interesse com os interesses do programa e dos orientadores.

Os estudos de Araujo e Amaral (2006) também revelaram grande importância da formação continuada de professores na Pós-graduação stricto sensu refletida em seus trabalhos como docentes.

Na pesquisa sobre os impactos de um mestrado profissional na atividade docente de seus estudantes, os autores constataram que a vivência das atividades do programa de mestrado propiciou condições para que os mestrandos desenvolvam ações fundamentadas em uma percepção mais ampla e reflexiva sobre os processos de ensino e aprendizagem, utilizando seus novos conhecimentos e diferentes metodologias e estratégias de ensino capazes de facilitar a aprendizagem de seus alunos. Essa modernização dos procedimentos didáticos e pedagógicos usados pelos mestrandos acarretou reflexos diretos sobre os ambientes escolares onde atuam, promovendo gradualmente mudanças necessárias no sistema educacional em curto prazo.

Portanto, fica evidente que as repercussões do mestrado profissional na vida pessoal e profissional dos mestrandos abrangem um largo espectro de fatores e elementos, reforçando a importância dessa modalidade de Pós-graduação stricto sensu como instrumento capaz de contribuir para que sejam processadas as transformações no sistema educacional do país, o que poderá ocorrer de maneira mais ampla e profunda na medida em que esses profissionais, com formação mais adequada, funcionem como agentes multiplicadores nos ambientes em que atuam, estimulando inclusive seus pares a também buscarem espaços semelhantes de aprimoramento (2006, p.165).

Segundo Alves e Costa-Hübes (2011), a formação continuada não é a panaceia da educação, porém pode contribuir oferecendo perspectivas e alternativas para a atuação do professor em sala de aula. É essencial que o governo e órgãos competentes continuem fomentando e ampliando a formação continuada de professores da educação básica, reconhecendo toda sua importância no trabalho facilitador de formar profissionais mais competentes proporcionando a possibilidade de ascensão tanto no exercício docente como no nível pessoal do professor. 


\section{autêntica}

\section{A PÓS-GRADUAÇÃO STRICTO SENSU E A FORMAÇÃO DE PROFESSORES DE PORTUGUÊS DA EDUCAÇÃO BÁSICA DO DISTRITO FEDERAL}

A Lei No 1.619, de 22 de agosto de 1997 criou a Escola de Aperfeiçoamento dos Profissionais da Educação - EAPE a qual compete, conforme o Art. $2^{\circ}$ da referida lei, planejar, promover, coordenar, avaliar e executar as atividades de aperfeiçoamento dos profissionais da rede pública de ensino do Distrito Federal. No Parágrafo único do Art. $2^{\circ}$, no desenvolvimento de suas atividades, a EAPE deve considerar as diretrizes político-pedagógicas adotadas na rede pública de ensino do Distrito Federal, bem como as exigências de capacitação relativas à Carreira Magistério e à Carreira Assistência à Educação. Portanto, a EAPE tem como função promover a formação continuada dos profissionais da Educação em consonância com as demandas da Rede Pública de ensino do DF, contribuindo para a educação de qualidade social e a valorização profissional dos educadores.

O Decreto $N^{\circ} 6.755$, de 29 de janeiro de 2009, institui, em seu $1^{\circ}$ Artigo, a Política Nacional de Formação de Profissionais do Magistério da Educação Básica, com a finalidade de organizar, em regime de colaboração entre a União, os Estados, o Distrito Federal e os Municípios, a formação inicial e continuada dos profissionais do magistério para as redes públicas da educação básica.

Art. 8: $\mathrm{O}$ atendimento às necessidades de formação continuada de profissionais do magistério dar-se-á pela indução da oferta de cursos e atividades formativas por instituições públicas de educação, cultura e pesquisa, em consonância com os projetos das unidades escolares e das redes e sistemas de ensino.

No mesmo Art. $8^{\circ}$ no $\S 2^{\circ}$, "as necessidades de formação continuada de profissionais do magistério serão atendidas por atividades formativas e cursos de atualização, aperfeiçoamento, especialização, mestrado ou doutorado".

A Portaria N ${ }^{\circ}$ 358, de 11 de novembro de 2005, da Secretaria de Estado de Educação do Distrito Federal traz em seu Anexo Único os critérios para avaliação das solicitações dos candidatos ao processo seletivo de Afastamento Remunerado para Estudos:

1. Os candidatos ao processo seletivo de afastamento remunerado para estudos serão classificados considerando o maior número de pontos obtidos, de acordo com os seguintes critérios:

A-VÍNCULO EMPREGATÍCIO - SEDF, 2 pontos - SEDF e outros, 1 ponto.

B-TEMPO PARA A CONCLUSÃO DO CURSO - 1 semestre, 5 pontos - 2 semestres, 4 pontos - 3 semestres, 3 pontos - 4 semestres, 2 pontos - 5 a 8 semestres, 1 ponto.

C- ÁREA DO CURSO - Educação/Organização do Trabalho Pedagógico em Sala de Aula, Avaliação da Aprendizagem e Formação Continuada dos Docentes da Educação Básica, 3 pontos - Educação/ Movimentos Sociais, Política e Gestão, 2 pontos - Estudos Específicos, 1 ponto.

D- HABILITAÇÃO / ATUAÇÃO NA SEDF - Igual à área do curso, 2 pontos - Afim com a área do curso, 1 ponto.

E-TEMPO DE SERVIÇO NA SEDF - Acima de 180 meses, 5 pontos - Mais de 120a 180 meses, 4 pontos - Mais de 84 a 120 meses, 3 pontos - Mais de 60 a 84 meses, 2 pontos - Mais de 36 a 60 meses, 1 ponto.

F- ASSIDUIDADE - Nenhuma falta injustificada, 3 pontos - De 1 a 5 faltas injustificadas, 2 pontos De 5 a 10 faltas injustificadas, 1 ponto. 


\title{
autêntica
}

\begin{abstract}
G- PARECER DA CHEFIA IMEDIATA - Favorável, 3 pontos - Pouco favorável, 2 pontos - Desfavorável / sem parecer, 1 ponto.

H- AFASTAMENTOS USUFRUÍDOS - Nenhum, 5 pontos - Até 6 meses, 4 pontos - Mais de 6 a 12 meses, 3 pontos - Mais de 12 a 24 meses, 2 pontos - Acima de 24 meses, 1 ponto.

2. Ocorrendo empate no total de pontos, serão adotados, sucessivamente, os seguintes critérios de desempate: $1^{\circ}$ maior pontuação obtida no somatório dos itens $A, C, E$ e $F ; 2^{\circ}$ maior tempo de serviço efetivo na SEDF; $3^{\circ}$ maior idade cronológica.

3. A avaliação do item F-Assiduidade basear-se-á na freqüência do servidor na SEDF nos vinte e quatro meses anteriores à data de pedido do Afastamento.
\end{abstract}

No item 1 letra C, a Secretaria de Educação do Distrito Federal elenca a área de Educação como alvo e prioritária para os professores de educação básica da rede pública do DF. Anualmente a EAPE lança uma circular com informações relativas ao processo seletivo para se obter Afastamento Remunerado para Estudos em Pós-graduação stricto sensu, que consta em seu texto como requisito para requerer o pleito do afastamento, que o curso do candidato seja compatível com sua habilitação ou área de atuação na SEDF, e que "as vagas de Mestrado destinam-se exclusivamente a cursos reconhecidos, realizados no Brasil por instituições credenciadas pelo órgão competente. As vagas de Doutorado serão destinadas prioritariamente aos servidores que estejam frequentando curso de Doutorado em Educação, ou área afim, desde que a linha de pesquisa seja voltada para atividades didático-pedagógicas da Carreira Magistério".

Segundo o Sistema Nacional de Pós-graduação (SNPG/CAPES) até 2004 o Conselho Técnico-Científico da Educação Superior - CTC-ES da Coordenação de Aperfeiçoamento de Pessoal de Nível Superior (CAPES) recomendou 103 cursos de Pós-graduação da área de Educação no Brasil. A partir desse ano, o crescimento se manteve constante com um pico em 2012, que apresentou 27 propostas recomendadas.

Nos últimos 10 anos, a Pós-graduação da área de Educação cresceu mais de 100\%, visto que em 2004 eram 103 cursos e em 2014 o número era 225.

\section{GRÁFICO 1: CRESCIMENTO CUMULATIVO DE CURSOS RECOMENDADOS NA ÁREA DE EDUCAÇÃO}

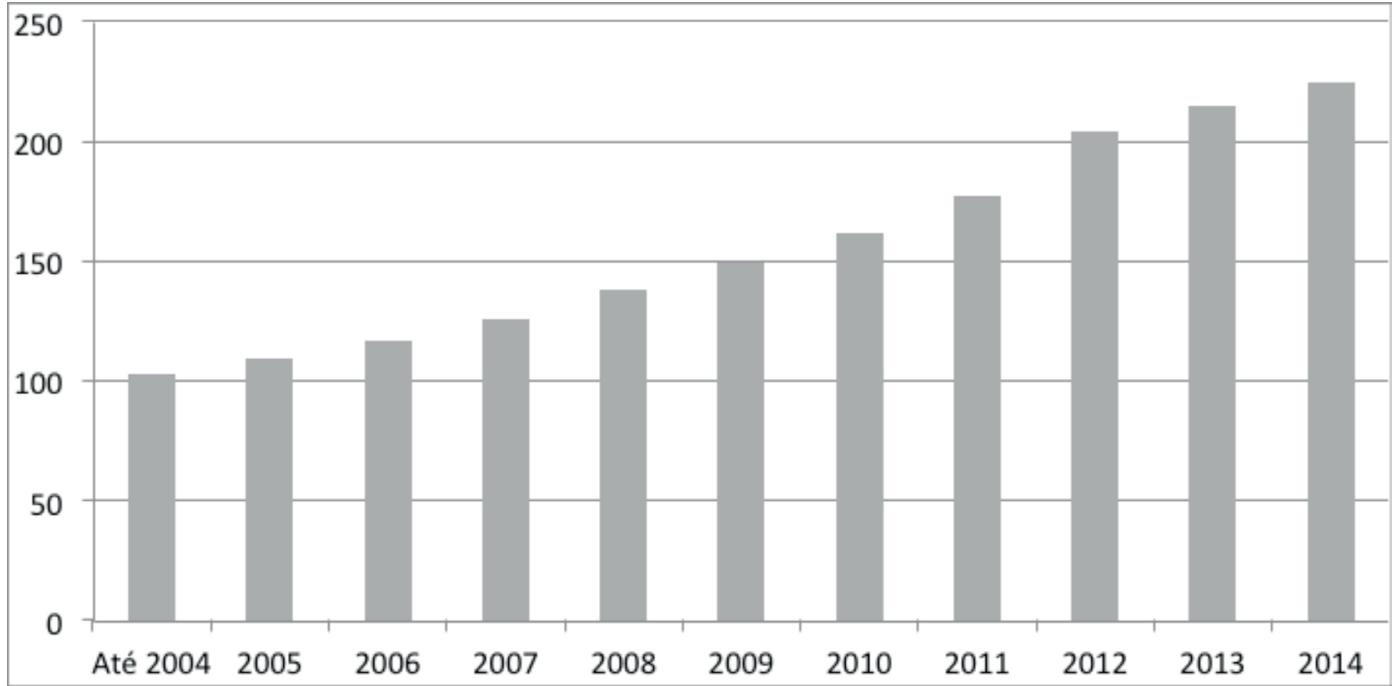

Fonte: SNPG/CAPES (2014) 


\section{autêntica}

O crescimento dos programas também pode ser observado ano a ano. Desde 2004 as recomendações de cursos de Pós-graduação da área de Educação são bem tímidas. Em 2012, houve um aumento expressivo de recomendações, chegando a 27. Nos anos seguintes, manteve-se a média dos anos anteriores, mas segundo o Documento de Área da Educação 2013, os programas da área nos últimos anos perceberam uma melhoria qualitativa, que pode ser inferida, principalmente, pela ampliação de programas de alto desempenho com bom nível de internacionalização, revelando uma maior consolidação da área em geral na última década.

GRÁFICO 2: RECOMENDAÇÕES ANO X ANO DOS PROGRAMAS DE PÓS-GRADUAÇÃO DA ÁREA DE EDUCAÇÃO PELA CAPES

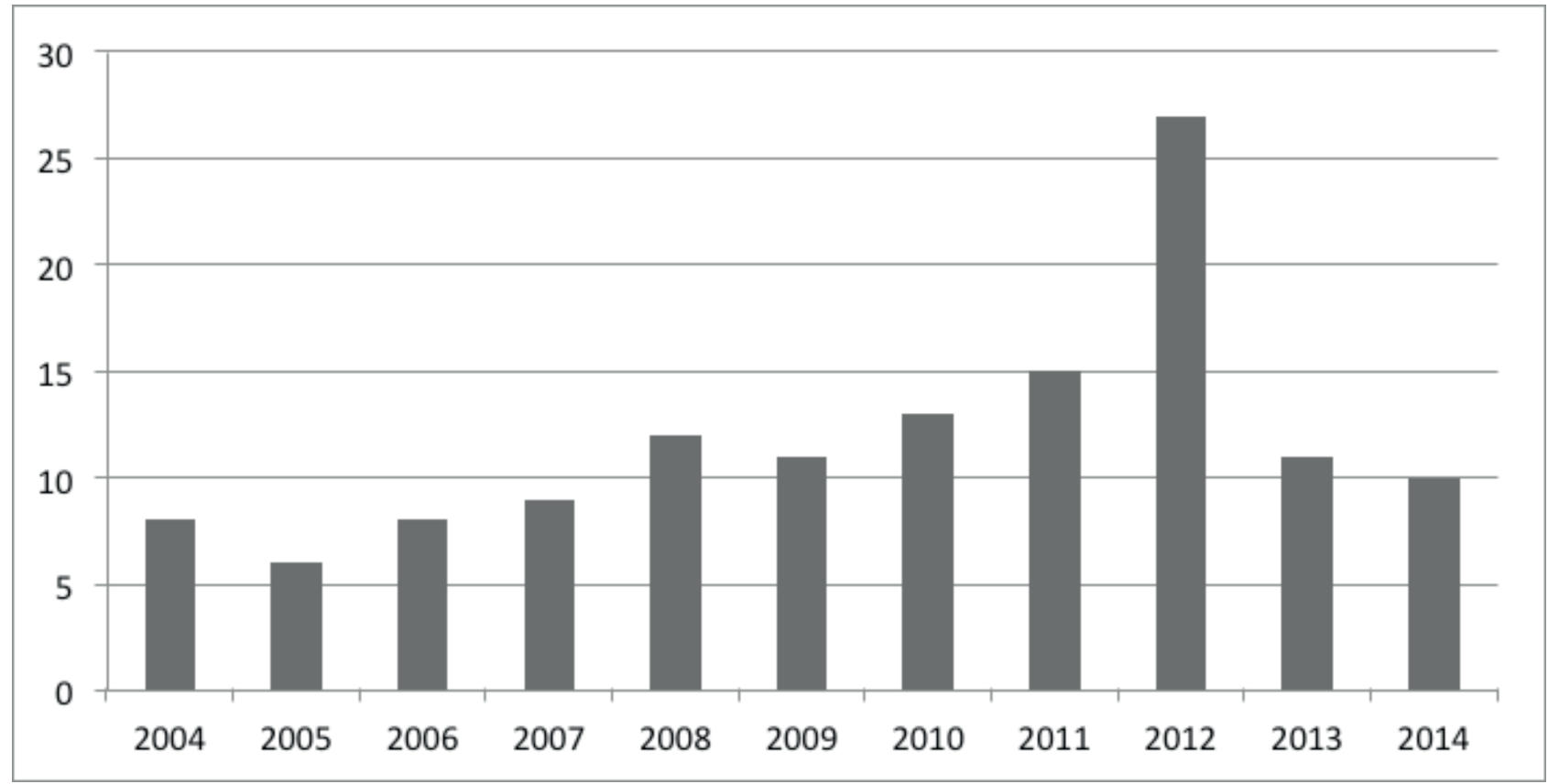

Fonte: SNPG/CAPES (2014)

Atualmente, a região Sudeste possui o maior número de Programas de Pós-graduação da área de Educação com 93 cursos. A região Norte é a mais carente em oferta de mestrados e doutorados em Educação com apenas 12 cursos. A região centro-oeste possui 24 cursos, sendo 5 no Distrito Federal. A região sul detém de $25 \%$ dos programas na área de Educação do Brasil com 56 cursos recomendados.

GRÁFICO 3: PERCENTUAL DE DISTRIBUIÇÃO ATUAL DOS PROGRAMAS DE PÓS-GRADUAÇÃO DA ÁREA DE EDUCAÇÃO POR REGIÃO

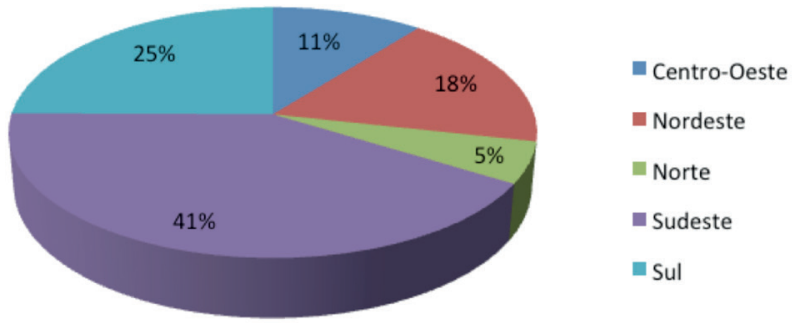


Até 2004, na área de Letras eram 124 cursos recomendados de Pós-graduação Stricto Sensu segundo o SNPG/CAPES. A partir desse ano é visível o crescimento continuo e a evolução do número de programas recomendados. Nos últimos 10 anos, a Pós-graduação da área de Letras cresceu mais de 80\%, com 124 cursos em 2004 e 230 em 2014.

GRÁFICO 4: CRESCIMENTO CUMULATIVO DE CURSOS RECOMENDADOS NA ÁREA DE LETRAS

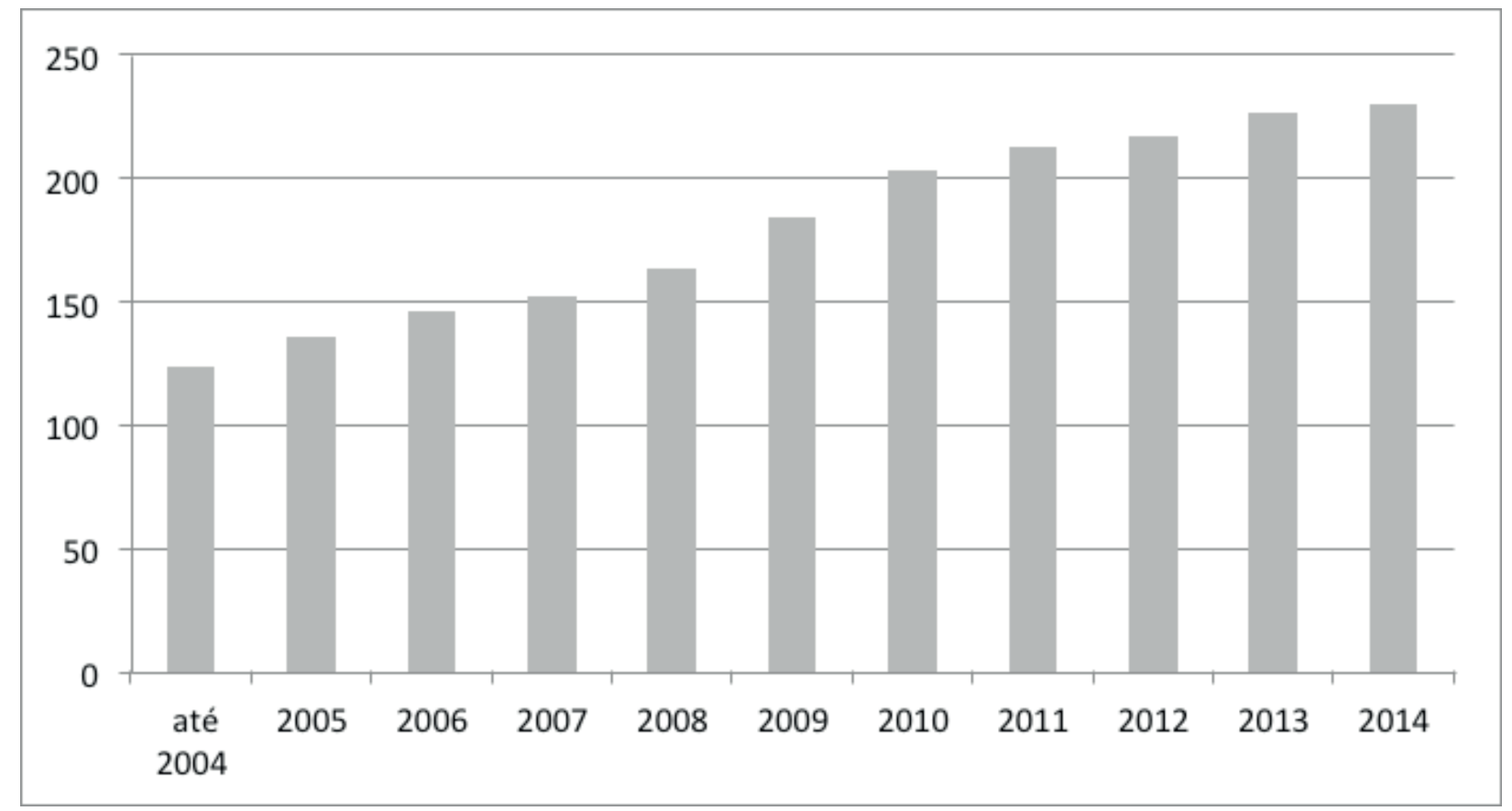

Fonte: SNPG/CAPES (2014)

O crescimento dos programas pode ser observado ano a ano. A partir de 2007, a Coordenação de Aperfeiçoamento de Pessoal de Nível Superior (CAPES) reconhecida pelo seu papel essencial na ampliação e consolidação da Pós-graduação stricto sensu (mestrado e doutorado) no Brasil, passou a atuar na formação de professores da educação básica aumentando a abrangência de suas ações no desenvolvimento de pessoal qualificado no Brasil e no exterior. No mesmo ano, o quantitativo de cursos aprovados caiu em comparação aos outros anos. A partir de 2008, o crescimento foi significativo, com um grande numero de cursos em Letras aprovados em 2009, 20 cursos.

Em 2012, houve uma queda de recomendações, somente 4, porém nesse ano a proposta do Mestrado Profissional em Letras - PROFLETRAS foi aprovada, o que pode ter motivado um menor número de recomendações, mas também de submissões de propostas, já que a proposta do PROFLETRAS foi apresentada com mais de 30 instituições participantes conforme tabela em anexo. 


\section{autêntica}

GRÁFICO 5: RECOMENDAÇÕES ANO X ANO DOS PROGRAMAS DE PÓS-GRADUAÇÃO DA ÁREA DE LETRAS PELA CAPES

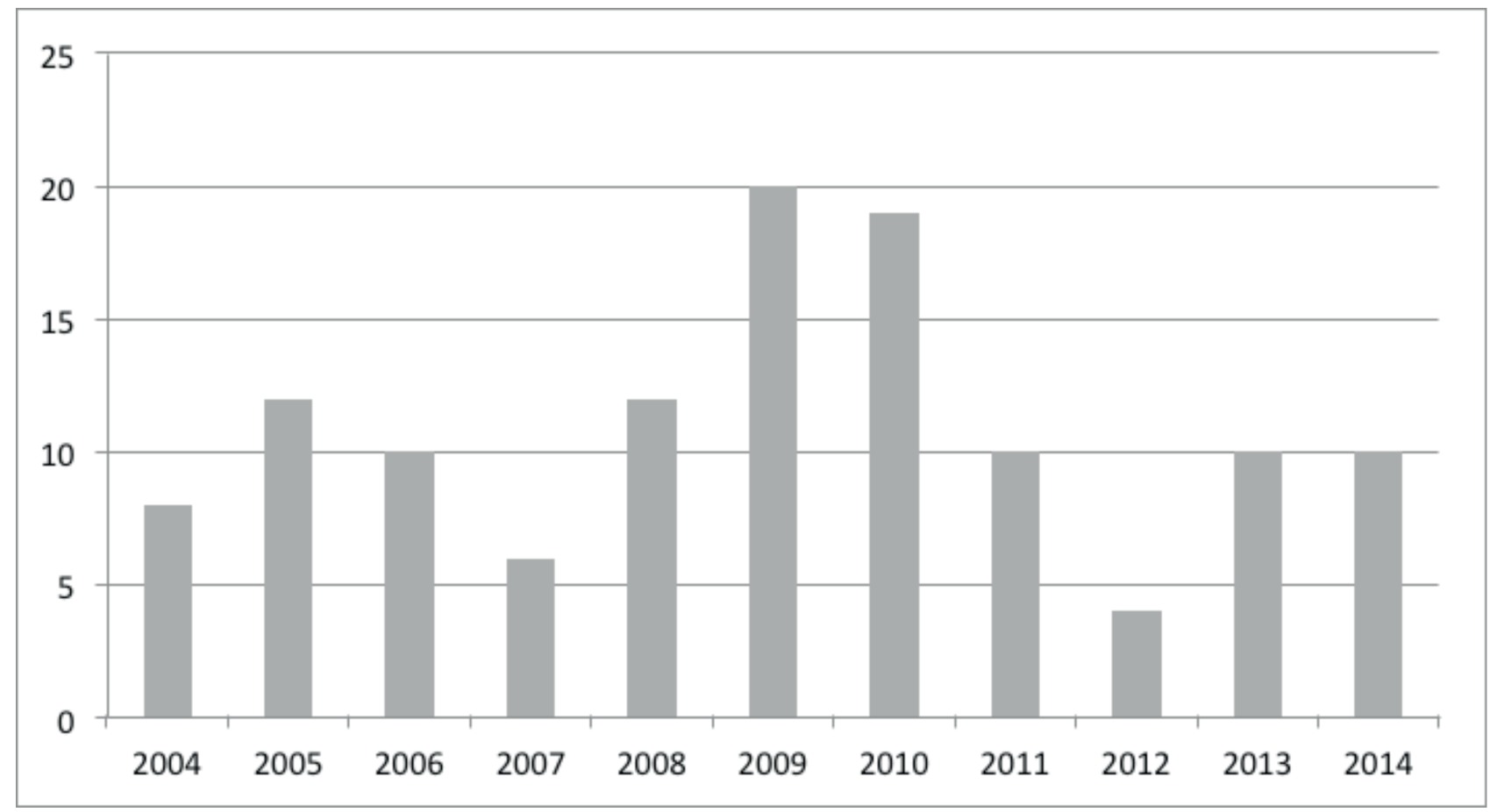

Fonte: SNPG/CAPES (2014)

Atualmente, a região Sudeste possui o maior número de Programas de Pós-graduação da área de Letras com 110 cursos. A região Norte é a mais carente em oferta de mestrados e doutorados em Letras com apenas 13 cursos. No PROFLETRAS somente 3 instituições de ensino são participantes: Universidade Federal do Acre - UFAC, Universidade Federal de Tocantins - UFT e Universidade Federal do Pará - UFPA.

Na primeira seleção nacional do PROFLETRAS, a UFPA foi a instituição que recebeu maior número de inscrições, totalizando 857 para apenas 26 vagas. O Distrito Federal possui 6 cursos de Pós-graduação stricto sensu na área de Letras. A região sul detém de $20 \%$ dos programas na área de Educação do Brasil com 46 cursos recomendados.

\section{GRÁFICO 6: PERCENTUAL DE DISTRIBUIÇÃO ATUAL DOS PROGRAMAS DE PÓS-GRADUAÇÃO DA ÁREA DE LETRAS POR REGIÃO}

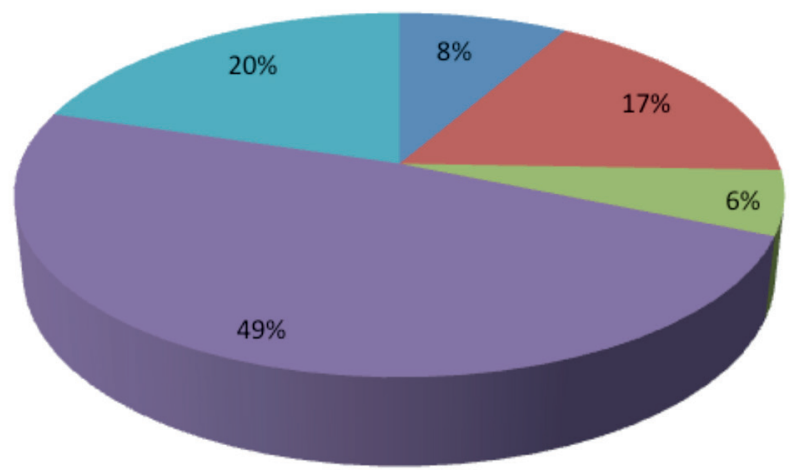

Centro-Oeste

Nordeste

Norte

Sudeste

m Sul 


\section{DOCENTE}

autêntica

A Lei n 3.318 de 11 de fevereiro de 2004, que dispõe sobre a carreira de Magistério Público do Distrito Federal e dá outras providências, apresenta no Capítulo II o desenvolvimento funcional dos professores da rede pública do DF e o Art. 16 trata sobre a qualificação profissional:

A qualificação profissional, que visa ao aprimoramento permanente do ensino e à promoção na carreira Magistério Público do Distrito Federal, ocorrerá por meio de participação em cursos de formação, treinamento, aprimoramento, especialização, mestrado e doutorado ou, ainda, em outras atividades de atualização profissional proporcionados pela Secretaria de Estado de Educação ou por instituições legalmente autorizadas, observados os programas prioritários e segundo normas a serem definidas por essa Secretaria.

O servidor da Carreira de Magistério Público do Distrito Federal faz jus à Gratificação de Titulação quando realiza qualificação em programas de Pós-graduação stricto sensu, considerando os títulos obtidos junto às instituições autorizadas ou reconhecidas pelo órgão competente, conforme os percentuais apresentados no Anexo Único da Portaria n 232, de 24 de agosto de 2004, que regulamenta a Lei n³.318/2004:

a) $55 \%$ (cinqüenta e cinco por cento), no caso de possuir Diploma de Doutorado, devidamente registrado pelo órgão competente;

b) $40 \%$ (quarenta por cento), no caso de possuir Diploma de Mestrado, devidamente registrado pelo órgão competente;

Lei anterior, de $n^{\circ} 771 / 1994$, estipulava $50 \%$ no caso de possuir título de doutor e $25 \%$ no caso de possuir título de mestre.

A quantidade de professores de educação básica de português atuantes na rede pública de ensino do DF vem diminuindo nos últimos anos, principalmente a partir de 2007 conforme gráfico abaixo, tendo uma diferença mais expressiva de 2007 com 4163 professores para 2014 com 3886, reduzindo seu quantitativo nesse período em $6 \%$.

\section{GRÁFICO 7: NÚMERO DE PROFESSORES DE EDUCAÇÃO BÁSICA DE PORTUGUÊS ATUANTES NA REDE PÚBLICA DE ENSINO DO DF ANO A ANO}

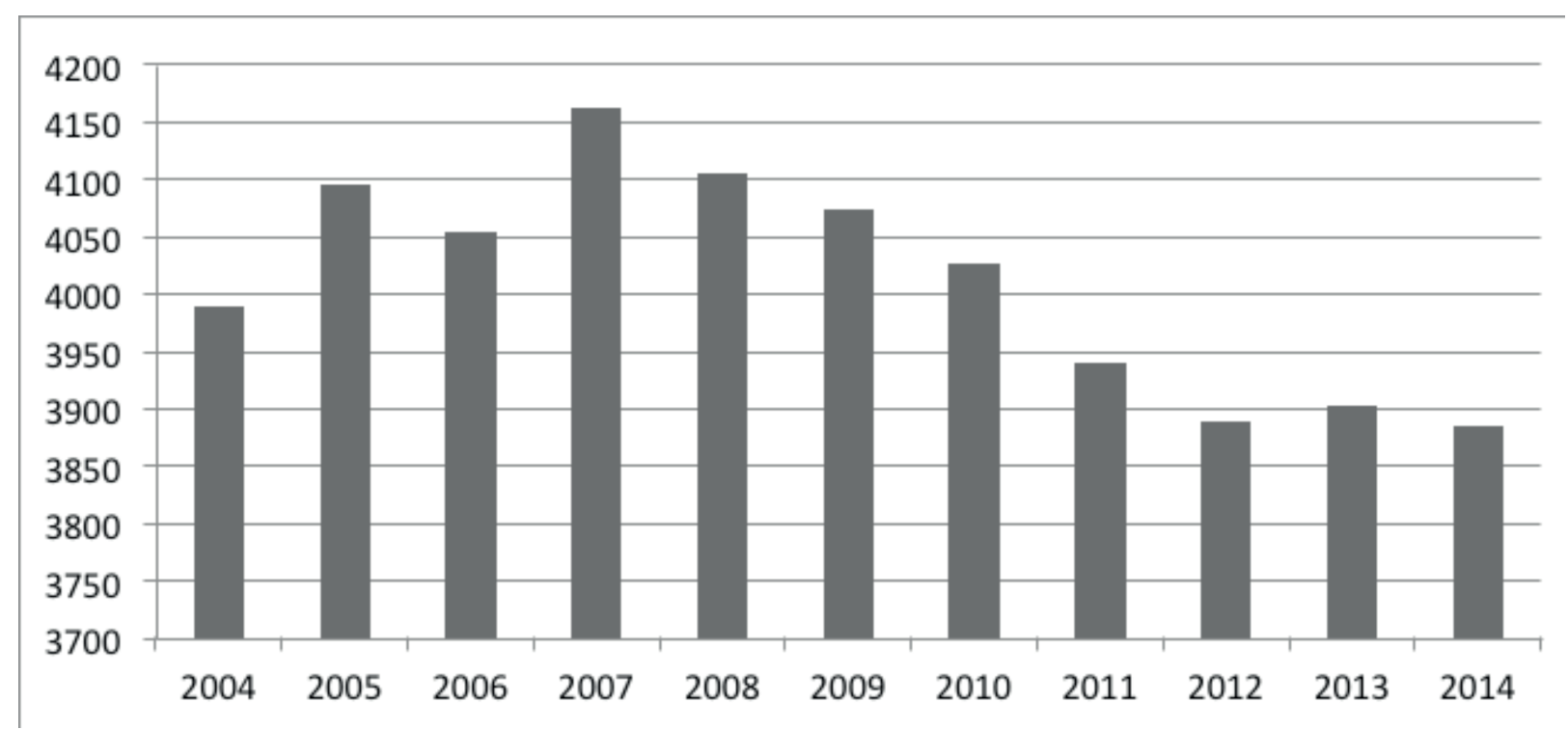

Fonte: Secretaria de Educação do GDF (2014). 


\section{autêntica}

A variação do número total de professores não foi grande nos últimos anos, mas conforme gráfico abaixo, o crescimento de professores titulados com mestrado no mesmo período evoluiu de forma significativa e constante, mais de 150\% de 2004 para 2014. É possível observar dois picos de crescimento de 2007 para 2008 com mais de 20 títulos de diferença, e de 2012 para 2013 com 30 títulos a mais.

GRÁFICO 8: CRESCIMENTO DO NÚMERO DE PROFESSORES DE EDUCAÇÃO BÁSICA DE PORTUGUÊS ATUANTES NA REDE PÚBLICA DE ENSINO DO DF TITULADOS COM MESTRADO

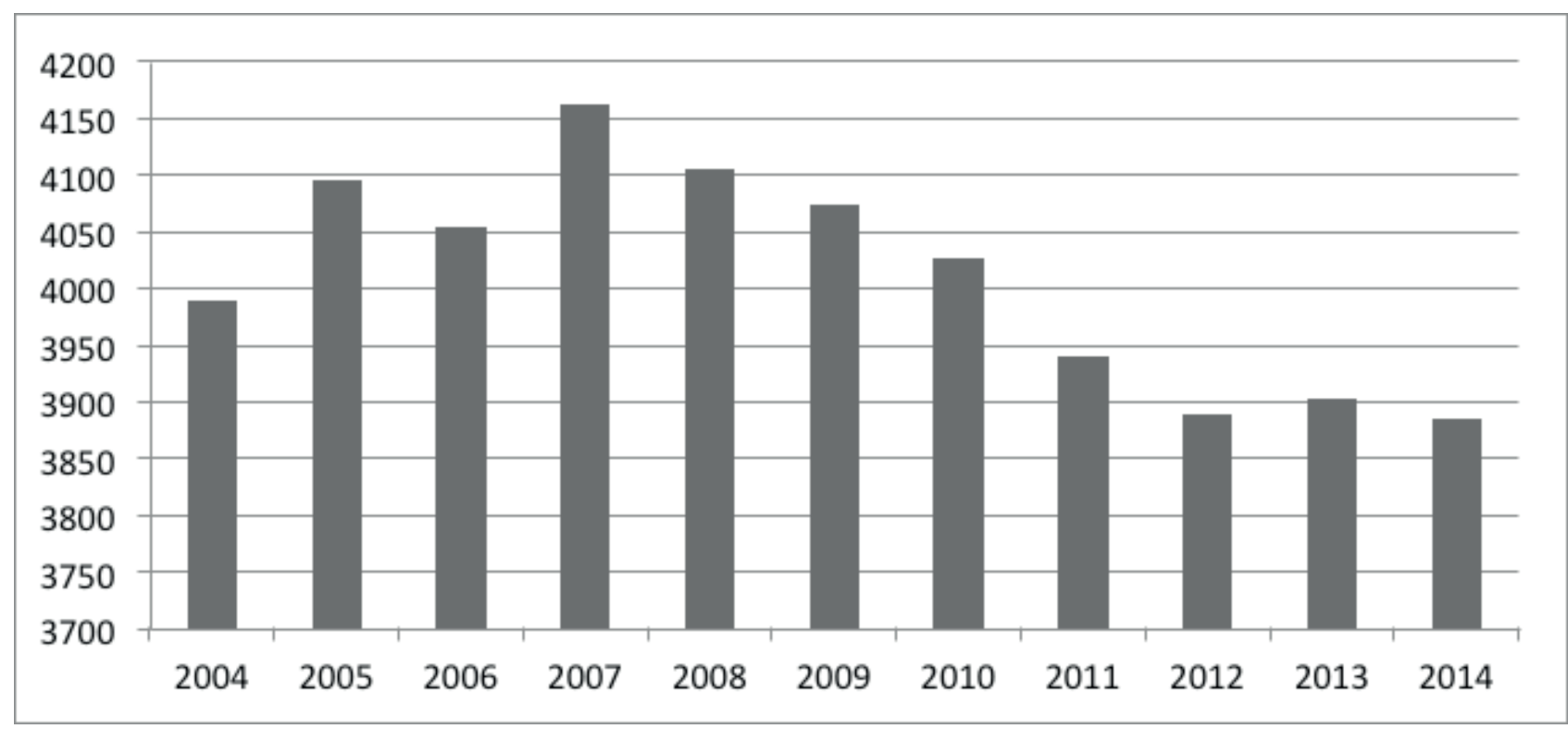

Fonte: Secretaria de Educação do GDF (2014).

Já o crescimento de professores titulados com doutorado apresentou uma variação mais diversificada. Manteve-se constante até 2007 e picos de crescimento em 2008 e a partir de 2012, conforme gráfico abaixo. Apesar das titulações de doutorado serem inferiores as de mestrado, a evolução de professores doutores nos últimos 10 anos foi de mais de 400 \%, variando de 6 títulos em 2004 para 31 em 2014. 
GRÁFICO 9: CRESCIMENTO DO NÚMERO DE PROFESSORES DE EDUCAÇÃO BÁSICA DE PORTUGUÊS ATUANTES NA REDE PÚBLICA DE ENSINO DO DF TITULADOS COM DOUTORADO

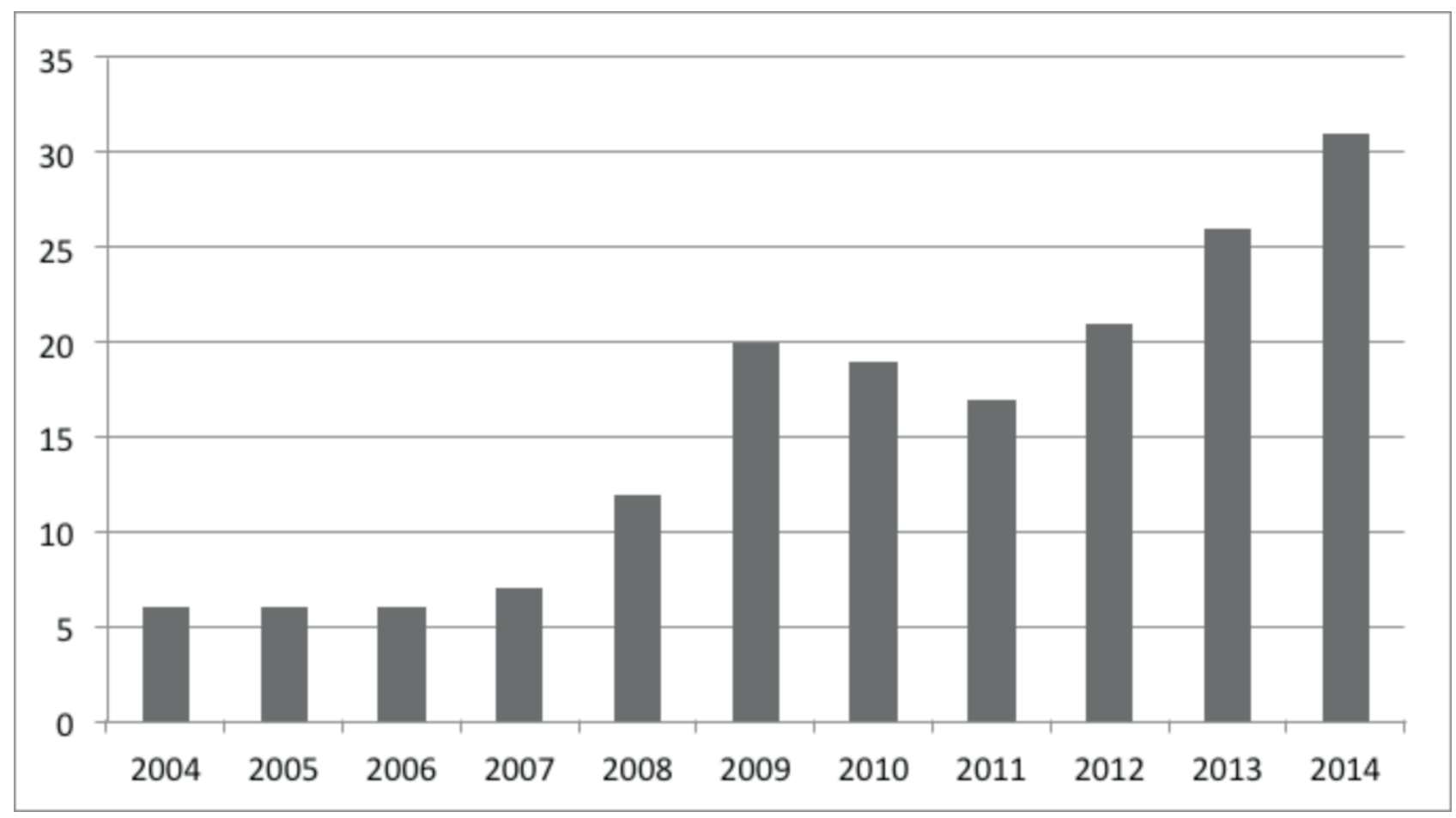

Fonte: Secretaria de Educação do GDF (2014).

Observando o gráfico abaixo, a quantidade de professores de educação básica de português atuantes na rede pública de ensino do DF titulados na Pós-graduação stricto sensu de 2004 a 2014 ainda é muito baixa em relação ao universo total de professores. Analisando 2014, o ano que mais houve titulação tanto no mestrado como no doutorado, ainda assim somente $6 \%$ dos professores titularam no mestrado e menos de $1 \%$ titulou doutorado. Obviamente analisando esses dados ainda estamos longe de alcançar meta de formar $50 \%$ dos professores da Educação Básica em nível de Pós-graduação lato e stricto sensu constante na Lei No 13.005/2014, que trata sobre o Plano Nacional de Educação - PNE para o decênio 2011-2020. Porém ao observar a evolução de titulações ano a ano é possível depreender que o crescimento tem sido relevante e sua evolução apresentou-se muito grande nos últimos 10 anos. 


\section{autêntica}

GRÁFICO 10: COMPARATIVO DO TOTAL DE PROFESSORES DE EDUCAÇÃO BÁSICA DE PORTUGUÊS ATUANTES NA REDE PÚBLICA DE ENSINO DO DF COM OS QUE POSSUEM TÍTULOS

\section{DE MESTRADO E DOUTORADO}

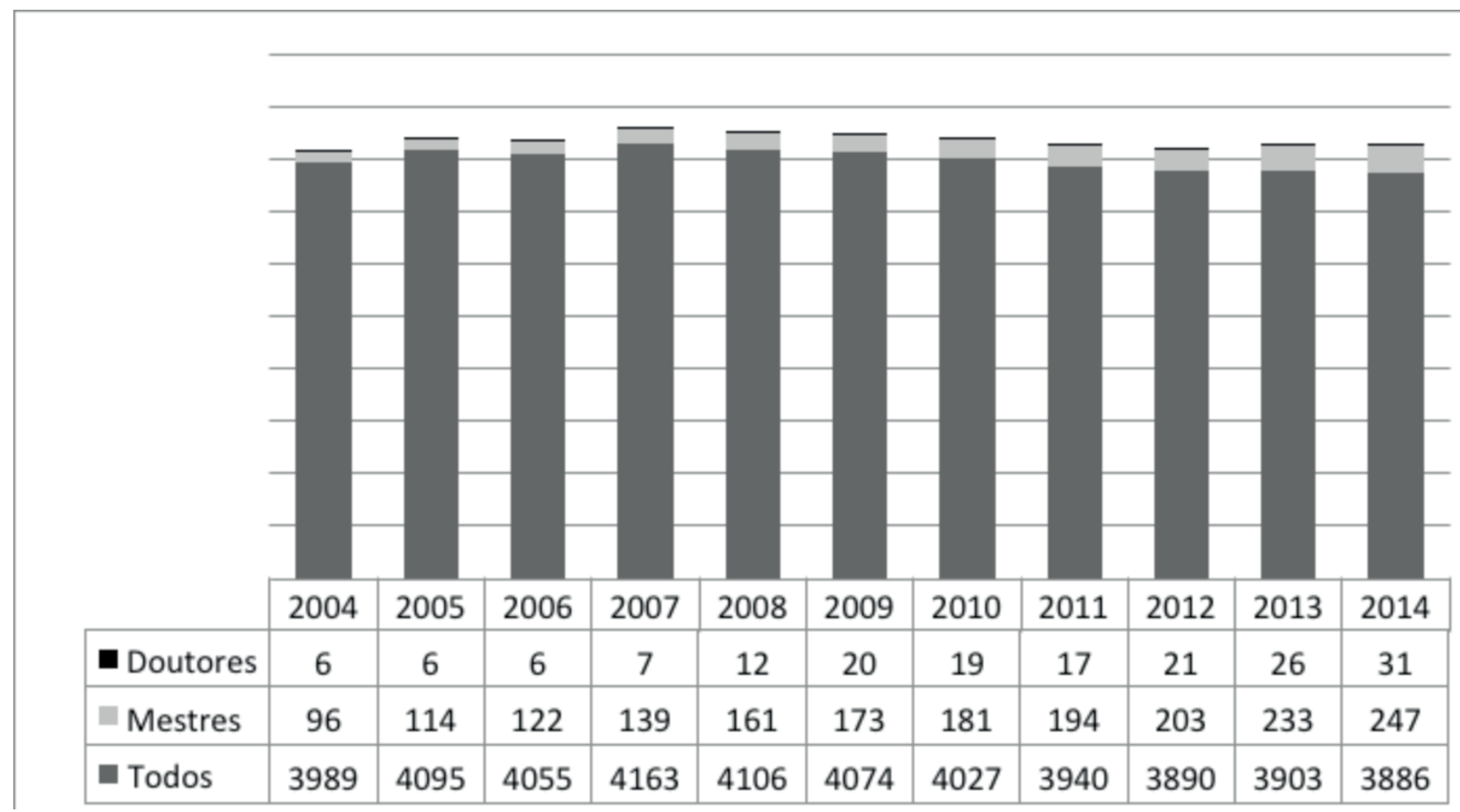

Fonte: Secretaria de Educação do GDF (2014).

Em 2007, com a Lei n 4075 a Gratificação de titulação foi transformada em "Progressão Horizontal" e foi incorporada aos vencimentos dos cargos de Professor de Educação Básica e de Especialista de Educação da Carreira Magistério Público do Distrito Federal. No Art. 13 da mesma lei, o governo assegura formação continuada para os professores da rede pública, mediante a oferta de cursos de qualificação e de aperfeiçoamento, sem prejuízo das atividades pedagógicas, com o objetivo de fomentar práticas educativas para a melhoria da qualidade do ensino.

$\S 1^{\circ}$ Os cursos de qualificação e aperfeiçoamento de servidores serão oferecidos pela Secretaria de Estado de Educação, diretamente ou por intermédio de instituições por ela contratadas, com base em levantamento prévio das necessidades e prioridades das instituições educacionais, devendo ser realizados no horário de trabalho.

$\S 2^{\circ}$ Fica garantido, anualmente, o afastamento remunerado de, no mínimo, $1 \%$ (um por cento) dos servidores ativos para a realização de cursos de mestrado ou de doutorado, a título de formação continuada, respeitados os critérios de conveniência e oportunidade da Administração.

O gráfico abaixo mostra o número de professores de português da educação básica do DF licenciados para cursar mestrado e/ou doutorado por ano, no período de 2004 a 2014. 
GRÁFICO 11: NÚMERO DE PROFESSORES DE PORTUGUÊS DA EDUCAÇÃO BÁSICA DO DF LICENCIADOS PARA CURSAR MESTRADO E/OU DOUTORADO ANO A ANO

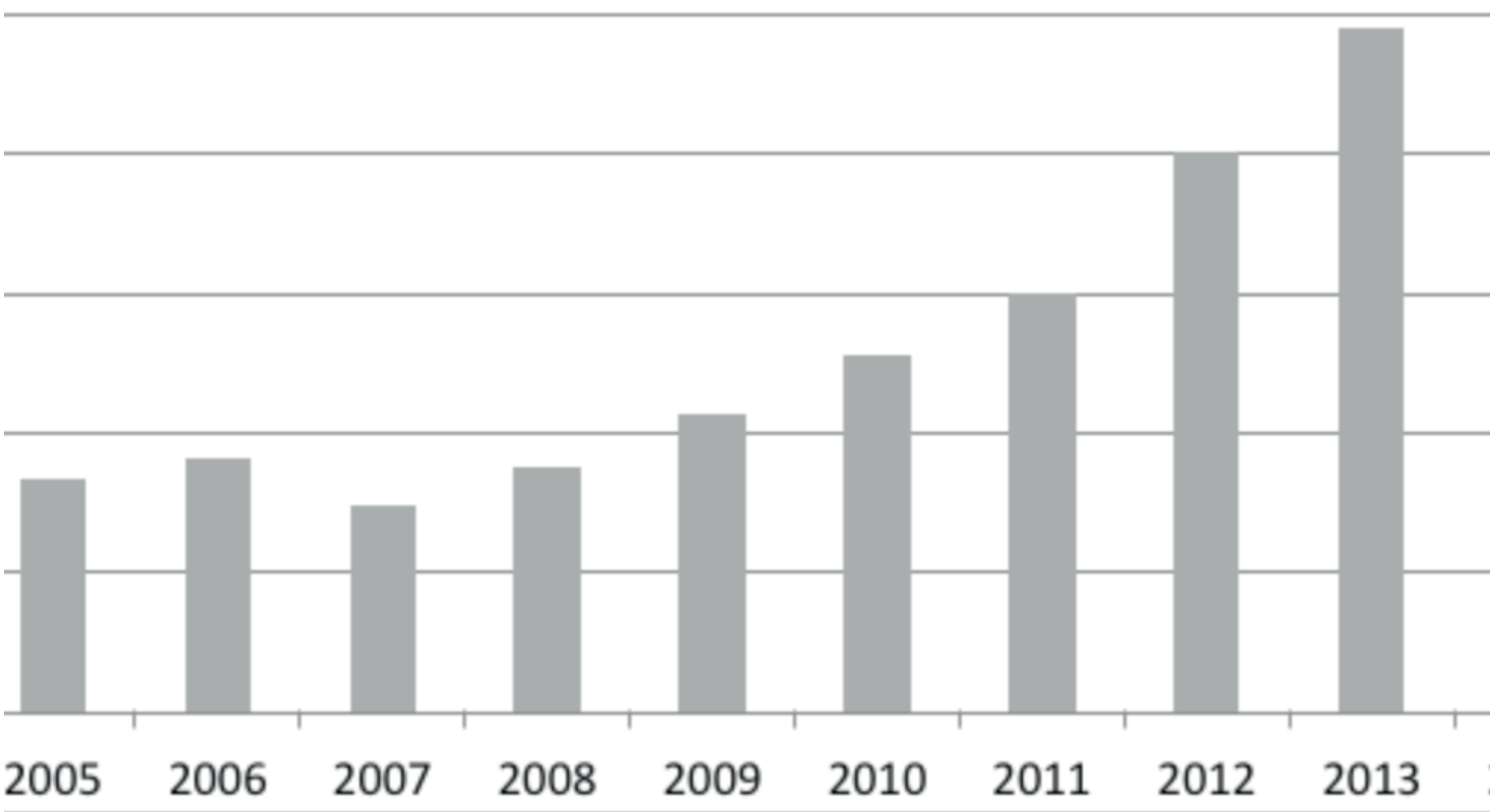

Fonte: Secretaria de Educação do GDF (2014).

Nos últimos 10 anos, houve um aumento progressivo de professores com licença de estudos para a Pósgraduação stricto sensu a partir de 2007, mesmo ano da publicação da Lei n 4075 que incorporou a Gratificação de titulação ao vencimento dos professores do DF e da Lei n 11.502 que atribuiu à CAPES o desafio de indução e fomento da formação inicial e continuada de professores para a educação básica. Observa-se no gráfico abaixo um aumento de mais de $300 \%$ de professores que se afastaram de suas atividades docentes de 2004 (58) para 2014 (258). 


\section{DOCENTE}

autêntica

GRÁFICO 12: COMPARATIVO DO NÚMERO DE PROFESSORES DE PORTUGUÊS DA EDUCAÇÃO BÁSICA DO DF LICENCIADOS PARA CURSAR MESTRADO E/OU DOUTORADO EM 2004 E 2014.

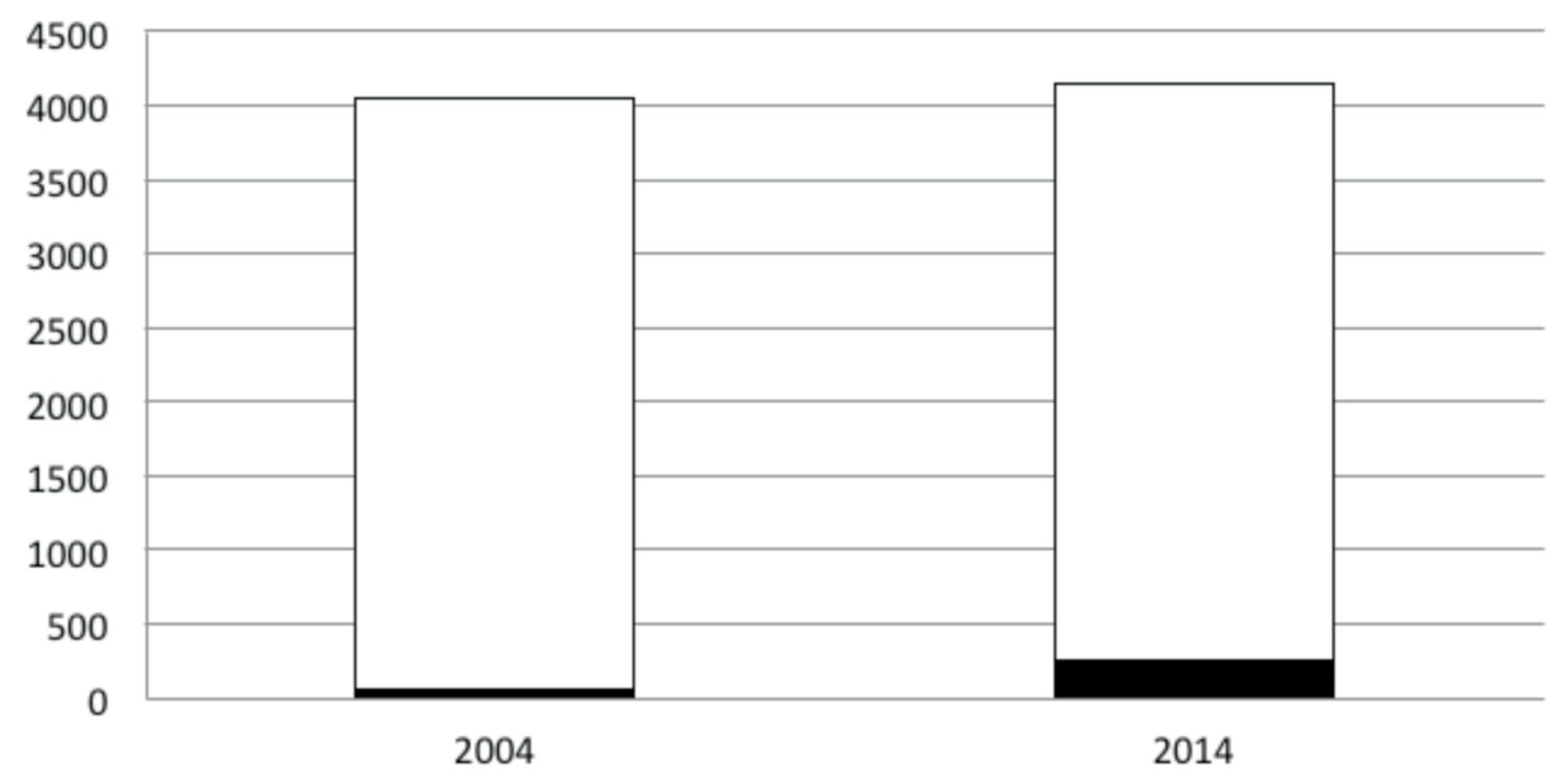

Fonte: Secretaria de Educação do GDF (2014). 


\section{CONSIDERAÇÕES FINAIS}

Este estudo científico apresenta um objetivo que visa auxiliar ações de formação continuada baseadas nas necessidades formativas dos professores de educação básica de português e na oferta de cursos de Pósgraduação stricto sensu na área de atuação.

Na pesquisa observou-se que nos últimos anos houve uma maior preocupação do governo com a qualidade do ensino brasileiro e com o incentivo de políticas públicas para desenvolver e alavancar a formação continuada de professores, especialmente os atuantes na educação básica. A capacitação docente e de recursos humanos diversos sempre foi a base dos Planos Nacionais de Pós-graduação. Com a entrada da CAPES no cenário de formação de professores da Educação Básica em 2007, a necessidade de uma ligação mais efetiva entre a Pós-graduação stricto sensu e a Educação Básica ficou mais forte e evidente. Com isso, a discussão de implementação de cursos de Pós-graduação stricto sensu voltados diretamente para a formação em grande escala de professores de Educação Básica foi realizada e amadurecida, e em 2010, o primeiro mestrado profissional com essas especificações foi aprovado e inserido no Sistema Nacional de Pós-graduação brasileiro, dando início à indução de formação de professores da educação básica, principalmente pública, nesse nível de ensino. Esses mestrados em rede nacional são semi-presenciais, portanto possuem várias as instituições envolvidas tornando o número de vagas ofertados bem superior as ofertadas nos cursos tradicionais presenciais.

É pertinente afirmar, em virtude da importância do tema, que as políticas públicas educacionais direcionadas para a formação continuada de professores são basilares e a formação contínua em si tem significativa potencialidade de dispensar aos professores o alcance de elementos teóricos e práticos fundamentais para uma atuação pedagógica mais eficiente conforme já estudado por Rigolon (2007), Leite (2010), Erickson (1989), Araujo e Amaral (2006) entre outros, promovendo assim melhoria na qualidade do ensino com consequente impacto relevante na sociedade.

Os dados levantados na pesquisa, cujo objetivo foi investigar o impacto do crescimento da Pós-graduação stricto sensu na formação de professores de português da educação básica que atuam na rede pública de ensino do DF, possibilitou comparar o crescimento da Pós-graduação stricto sensu nos últimos 10 anos com a relação de professores da Educação Básica atuantes na rede pública de ensino do DF que ingressaram e obtiveram os títulos de mestrado e/ou doutorado, no mesmo período.

A partir da análise do gráfico abaixo, que compila os dados já apresentados anteriormente, observa-se que os programas de Pós-graduação stricto sensu nas áreas de Educação e Letras, propícias para a formação dos professores de português, teve seu maior índice de crescimento em 2010 com 32 cursos recomendados, obtendo nos últimos 10 anos mais de 100\% de evolução, lembrando que em 2012 houve a recomendação do curso em rede Mestrado Profissional em Letras - PROFLETRAS criado para induzir a capacitação dos professores de português do ensino básico.

A titulação em Mestrado dos professores da Educação Básica atuantes na rede pública de ensino do DF teve seu maior índice de crescimento em 2013 com 30 titulações, obtendo nos últimos 10 anos mais de $150 \%$ de evolução. 


\section{autêntica}

A titulação em Doutorado dos professores da Educação Básica atuantes na rede pública de ensino do DF teve seu maior índice de crescimento em 2009 com 8 titulações, obtendo nos últimos 10 anos mais de $400 \%$ de evolução.

GRÁFICO 13: COMPARATIVO DA EVOLUÇÃO DOS PROGRAMAS DE PÓS-GRADUAÇÃO STRICTO SENSU NAS ÁREAS DE EDUCAÇÃO E LETRAS COM O CRESCIMENTO DE PROFESSORES DE PORTUGUÊS DA EDUCAÇÃO BÁSICA DO DF TITULADOS NO MESTRADO E NO DOUTORADO.
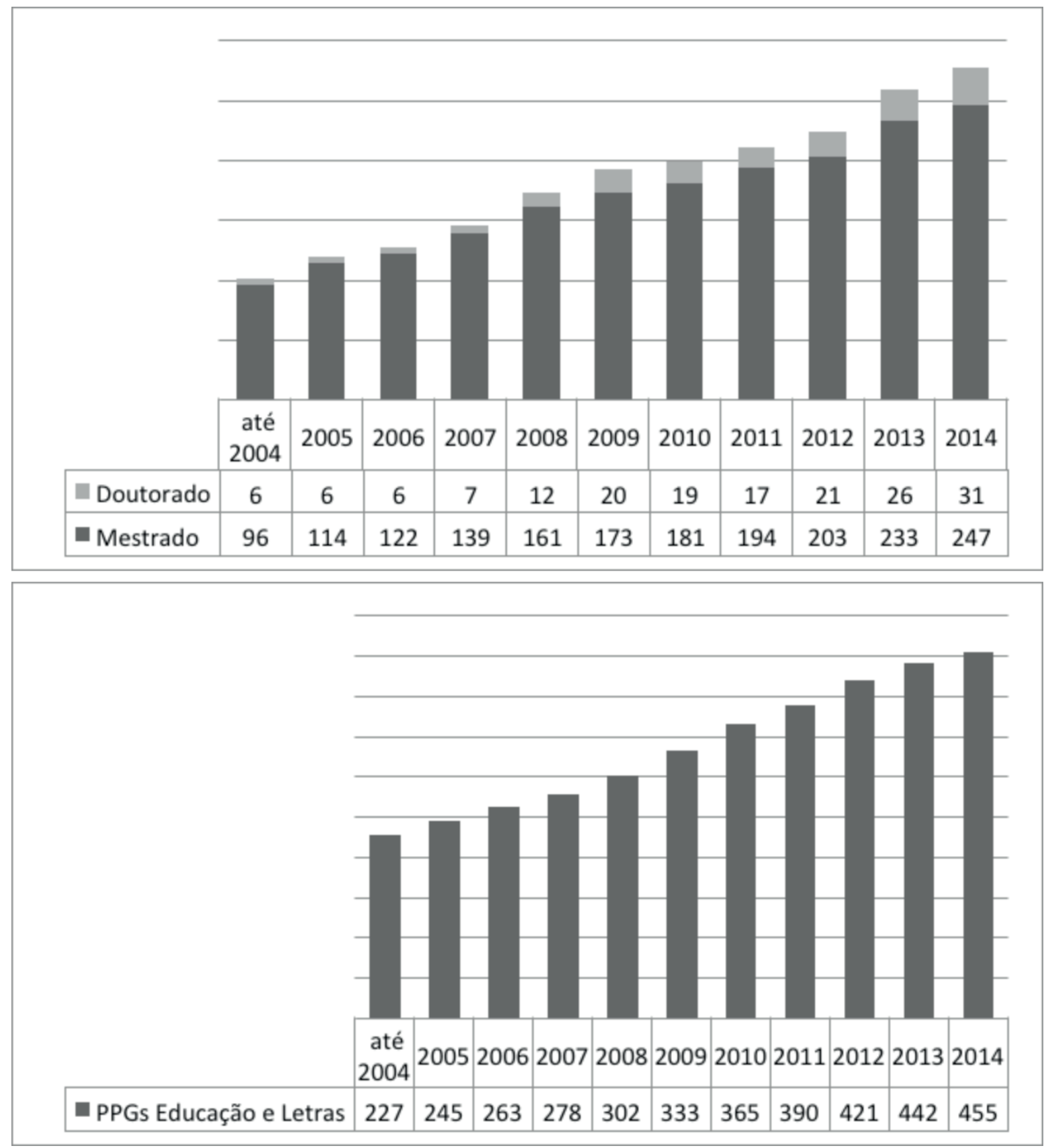

Pode-se concluir que o impacto do crescimento da Pós-graduação stricto sensu na formação de professores de português da educação básica que atuam na rede pública de ensino do DF, foi positivo nos últimos 10 anos, possibilitando observar a evolução da formação continuada dos professores nesse nível de ensino. 
O estudo também foi oportuno para mostrar que as legislações, políticas públicas e incentivos voltados para a formação continuada de professores de educação básica, como plano de carreira e afastamento para realização dos cursos de Pós-graduação stricto sensu dos professores do DF, estão caminhando para a valorização e capacitação desse profissional, bem como para o alcance das metas do Plano Nacional de Educação - PNE para o decênio 2011-2020.

A questão inicial, que deu origem a esta pesquisa, obteve resposta inteiramente positiva. O crescimento da Pós-graduação stricto sensu evoluiu juntamente com a formação nesse nível de ensino de professores de português da educação básica que atuam na rede pública de ensino do DF. Mesmo que, no universo atual de 3886 professores, pouco mais de $6 \%$ possuem mestrado e menos de $1 \%$ possuam doutorado, a evolução de titulações nos últimos 10 anos é surpreendentemente alta, mostrando que a importância e preocupação com formação continuada de professores é uma realidade com ações de fomento em andamento e que, apesar de toda sua evolução nos últimos anos, carece de um maior esforço no aumento de professores titulados anualmente, tendo como propósito maior as transformações no sistema educacional do país a partir do aprimoramento da atuação docente atualizando e desenvolvendo conhecimentos. 


\section{REFERÊNCIAS}

ALVES, A.G.K. ; COSTA-HÜBES, T. C. . Formação Continuada de Professores e Índices de Desenvolvimento da Educação Básica: o processo e o produto. In: I Congresso Internacional de Pesquisa em Letras no Contexto Latino-Americano e X Seminário Nacional de Literatura, História e Memória, 2011, Cascavel. Anais do I Congresso Internacional de Pesquisa em Letras no Contexto Latino-Americano e X Seminário Nacional de Literatura, História e Memória. Cascavel: EDUNIOESTE, 2011. v. 1.

ARAUJO, Mauro Sergio Teixeira de, AMARAL, Luiz Henrique. Impactos do Mestrado Profissional em Ensino de Ciencias e Matematica da Unicsul sobre a atividade docente de seus estudantes: do processo de reflexao as transformacoes na pratica pedagogica. R B P G - Revista Brasileira de Pos-Graduacao, Brasilia, v.3, n.5, p.150-166, jun 2006.

CAPES. I PNPG - Plano Nacional de Educação. Disponível em: <http://www.capes.gov.br/images/stories/ download/editais/I_PNPG.pdf> Acessado em 07 ago. 2014.

CAPES. II PNPG - Plano Nacional de Pós-graduação 1982 - 1985. Disponível em: <https://www.capes. gov.br/images/stories/download/editais/II_PNPG.pdf> Acessado em 07 ago. 2014.

CAPES. III PNPG Plano Nacional de Pós-graduação 1986 - 1989. Disponível em: <https://www.capes.gov. br/images/stories/download/editais/III_PNPG.pdf> Acessado em 07 ago. 2014.

CAPES. PNPG Plano Nacional de Pós-graduação 2005 - 2010. Disponível em: <https://www.capes.gov.br/ images/stories/download/editais/PNPG_2005_2010.pdf> Acessado em 07 ago. 2014.

CAPES. PNPG Plano Nacional de Pós-graduação 2011 - 2020. Disponível em: <http://www.capes.gov.br/ images/stories/download/PNPG_Miolo_V2.pdf> Acessado em 07 ago. 2014.

CAPES. Sistema Nacional de Pós-graduação (SNPG). Diretoria de Avaliação.

ERICKSON, F. Métodos Cualitativos de Investigación sobre la Enseñanza. In: WITTROCK, M. C. La investigación de la enseñanza, II - métodos cualitativos y de observación. Barcelona: Paidós Educador, MEC, 1989.

GATTI, Bernadete A. Análise das políticas para formação continuada no Brasil, na última década. Revista Brasileira de Educação, v. 13, n. 37, p. 57-70, jan/abr. 2008.

INEP. Desempenho de alunos melhora com professor capacitado. Disponível em: <http://portal.inep.gov. br/visualizar/-/asset_publisher/6AhJ/content/desempenho-de-alunos-melhora-com-professor-capacitado> Acesso em 07 ago. 2014.

INEP. Sistema de Avaliação da Educação Básica (Saeb). Disponível em: <http://portal.inep.gov.br/web/ saeb/aneb-e-anresc> Acesso em 07 ago. 2014.

LEITE, Yoshie Ussami Ferrari et all. Necessidades formativas e formação continua de professores de redes municipais de ensino. Associação Nacional de Pós-graduação e Pesquisa em Educação, $33^{a}$ Reunião 
Anual da ANPED, 2010, Caxambu. Disponível em: ‘http://33reuniao.anped.org.br/33encontro/app/webroot/ files/file/Trabalhos\%20em\%20PDF/GT08-6543--Int.pdf). Acesso em: 03 de outubro de 2014.

LÜDKE, Hermengarda Alves Ludke Menga ; RODRIGUES, Priscila Andrade Magalhães ; PORTELLA, V. C. . O mestrado como via de formação de professores da educação básica para a pesquisa. RBPG. Revista Brasileira de Pós-graduação, v. 9, p. 59-63, 2012.

NUNES, Terezinha. Dificuldades na Aprendizagem da Leitura. Teoria e prática. São Paulo: Cortez, 1992.

RIGOLON, W. A formação continuada de professores alfabetizadores. 2007. Dissertação (Mestrado) Pontifícia Universidade Católica de São Paulo, São Paulo.

Circular No 39 /2013-EAPE de 23 de maio de 2013. Regulamenta Afastamento Remunerado para Estudos entre os servidores das Carreiras Magistério Público e Assistência à Educação. Disponível em: <http:// www.sinprodf.org.br/wp-content/uploads/2014/05/n\% C2\% BA-39-afastamento-remunerado-para-estudos. pdf> Acessado em: 05 nov. 2014.

Decreto $N^{\circ} 26.358$, de 11 de novembro de 2005. Dispõe sobre a estrutura orgânica da Secretaria de Estado de Cultura do Distrito Federal. Disponível em: <http://www.buriti.df.gov.br/ftp/diariooficial/2005/11_ Novembro/DODF\%20215\%2014-11-2005/Se\%C3\%A7\%C3\%A3o01-\%20215.pdf> Acesso em: 05 nov. 2014.

Decreto $N^{\circ} 6.755$, de 29 de janeiro de 2009. Institui a Política Nacional de Formação de Profissionais do Magistério da Educação Básica, disciplina a atuação da Coordenação de Aperfeiçoamento de Pessoal de Nível Superior -CAPES no fomento a programas de formação inicial e continuada, e dá outras providências. Disponível em: <http://www.planalto.gov.br/ccivil_03/_ato2007-2010/2009/decreto/d6755.htm>. Acessado em: 05 nov. 2014.

Decreto $n^{\circ}$ 74.299, de 18 de Julho de 1974. Dispõe sobre a Coordenação de Aperfeiçoamento de Pessoal de Nível Superior (CAPES) e dá outras providências. Disponível em: <http://www2.camara.leg.br/ legin/fed/decret/1970-1979/decreto-74299-18-julho-1974-422808-publicacaooriginal-1-pe.html> Acessado em: 05 nov. 2014.

Indicador de Alfabetismo Funcional (INAF) - BRASIL 2001 a 2011. Disponível em: <http://www.ipm. org.br/ipmb_pagina.php?mpg=4.02.01.00.00\&ver=por> Acesso em: 05 nov. 2014.

Lei n. ${ }^{\circ} 1.619$, de 22 de agosto de 1997. Cria a Escola de Aperfeiçoamento dos Profissionais da Educação - Eape e dá outras providências. Disponível em: <http://www.tc.df.gov.br/SINJ/Arquivo.ashx?id_norma_consolidado=49577>. Acessado em: 05 nov. 2014.

Lei n 4.075, de 28 de dezembro de 2007. Dispõe sobre a Carreira Magistério Público do Distrito Federal e dá outras providências. Disponível em: <http://www.sinprodf.org.br/wp-content/uploads/2011/02/ planonovaredacao.pdf>. Acessado em: 05 nov. 2014.

Lei $n^{\circ} 771$, de 28 de setembro de 1994. Institui percentual, como parcela autônoma, incidente sobre o vencimento dos integrantes da Carreira Magistério Público do Distrito Federal. Disponível em: <http://www. tc.df.gov.br/ice4/legislacao/lei_ord_771_94.html>. Acessado em: 05 nov. 2014. 


\section{DOCENTE}

autêntica

Lei $n^{\circ} 11.502$, de 11 de julho de 2007. Modifica as competências e a estrutura organizacional da fundação Coordenação de Aperfeiçoamento de Pessoal de Nível Superior - CAPES, de que trata a Lei no 8.405, de 9 de janeiro de 1992; e altera as Leis nos 8.405, de 9 de janeiro de 1992, e 11.273, de 6 de fevereiro de 2006, que autoriza a concessão de bolsas de estudo e de pesquisa a participantes de programas de formação inicial e continuada de professores para a educação básica. Disponível em: <http://www.planalto.gov. br/ccivil_03/_Ato2007-2010/2007/Lei/L11502.htm> Acesso em: 07 ago. 2014.

Lei no 13.005, de 25 de junho de 2014. Aprova o Plano Nacional de Educação - PNE e dá outras providências. Disponível em: <http://www.planalto.gov.br/ccivil_03/_Ato2011-2014/2014/Lei/L13005.htm> Acesso em: 07 ago. 2014.

Lei $n^{\circ}$ 3.318, de 11 de fevereiro de 2004. Dispõe sobre a carreira Magistério Público do Distrito Federal e dá outras providências. Disponível em: <http://www.sinprodf.org.br/wp-content/uploads/2011/03/ lei-n\%C2\%BA-3.318-de-11-de-fevereiro-de-2004.pdf>. Acessado em: 05 nov. 2014.

Portaria $n^{\circ} 232$, de 24 de agosto de 2004. Aprova normas para a Gratificação de Titulação da Carreira Magistério Público do Distrito Federal. Disponível em: <http://saedf.org.br/site/arquivos/legislacao/ PORTARIA\% 20N\%BA\%20233,\%20DE\%2024\%20DE\%20AGOSTO\%20DE\%202004\%20-\%20GATA.pdf> Acesso em: 05 nov. 2014.

Portaria $n^{\circ} 358$, de 11 de novembro de 2005. Aprovar os critérios para avaliação das solicitações dos candidatos ao processo seletivo de Afastamento Remunerado para Estudos. Disponível em: <http://www. sinprodf.org.br/wp-content/uploads/2011/04/portaria-n-358-de-11-de-novembro-de-2005.pdf> Acesso em: 05 nov. 2014. 
